\title{
Michel Biard (dir.), La Révolution française. Une histoire toujours vivante
}

\section{Guillaume Mazeau}

\section{(2) OpenEdition \\ Journals}

Édition électronique

URL : https://journals.openedition.org/ahrf/11730

DOI : $10.4000 /$ ahrf. 11730

ISSN : 1952-403X

Éditeur :

Armand Colin, Société des études robespierristes

Édition imprimée

Date de publication : 1 septembre 2010

Pagination : 196

ISBN : 978-2-200-92633-5

ISSN : 0003-4436

Référence électronique

Guillaume Mazeau, « Michel Biard (dir.), La Révolution française. Une histoire toujours vivante »,

Annales historiques de la Révolution française [En ligne], 361 | juillet-septembre 2010, mis en ligne le 22 mars 2011, consulté le 24 avril 2022. URL : http://journals.openedition.org/ahrf/11730 ; DOI : https:// doi.org/10.4000/ahrf.11730

Ce document a été généré automatiquement le 24 avril 2022.

Tous droits réservés 


\title{
Michel Biard (dir.), La Révolution française. Une histoire toujours vivante
}

\author{
Guillaume Mazeau
}

\section{RÉFÉRENCE}

Michel Biard (dir.), La Révolution française. Une histoire toujours vivante, Paris,

Tallandier, 2010, 446 p. ISBN 978-2-84734-638-1, $27 €$

1 Ce livre en est la preuve : n'en déplaise aux noirs auteurs des Livres Noirs, l'histoire de la Révolution française est encore chaude. Après avoir organisé un colloque sur « les " politiques de la Terreur, Michel Biard continue son utile entreprise de rassemblement et de diffusion des recherches universitaires, démontrant que plus de deux siècles après, le passé révolutionnaire reste un enjeu à la fois scientifique et politique dans notre société si inquiète d'elle-même.

2 Sans doute appelé à devenir un classique de l'histoire érudite et vulgarisée, cet ouvrage collectif peut d'abord dérouter le lecteur: l'écueil du Livre Blanc a été évité, mais l'ensemble relève d'une histoire inhabituellement engagée. L'ambition de restituer une « histoire vivante » de la Révolution, que Lenoir de La Roche appelait de ses vœux au moment de la création du poste d'historiographe de la République (Moniteur du 3 frimaire an IV), place cette entreprise dans la tradition de l'histoire républicaine considérée comme un outil pédagogique d'émancipation. L'identité du lectorat visé ne se laisse pas non plus aisément définir. Ni réservé aux étudiants ni aux universitaires sans non plus pouvoir prétendre toucher le très grand public, ce livre relève d'un genre hybride, trop rare dans l'édition en sciences humaines : le manuel savant, à la fois clair et rigoureux. Les textes, écrits simplement, sont assortis de notes de bas de page et de courtes bibliographies qui permettront aux curieux d'en savoir davantage. L'ensemble s'ouvre hélas sur un possible malentendu qu'il faut vite dissiper. Non, ce livre n'est ni 
une énième charge contre Furet, ni une répétition des querelles du Bicentenaire, contrairement à ce que pourrait faire croire la préface signée par Michel Vovelle, jamais avare de traits saillants. Ainsi, l'expression « Soboul est mort, Furet est mort et moi-même je ne me sens pas très bien ", p. 21, est destinée à devenir une phrase culte d'une historiographie de combat pourtant un peu déconnectée des débats actuels.

Le choix des 27 thèmes, abordés par des chercheurs pour la plupart confirmés, répond à des ambitions forcément différentes. Déconstruisant les idées reçues, les auteurs réussissent le plus souvent à rassembler et à vulgariser les recherches, récentes ou non, qui nuancent ou battent en brèche les légendes noires. Ainsi, le profane apprendra que la Révolution fut une expérience bien plus complexe que la décadence économique (Guy Lemarchand), scientifique et culturelle (Patrice Bret, Philippe Bourdin, Philippe de Carbonnières et Serge Bianchi) ou même morale (contribution de Jean-Jacques Clère sur la famille), que l'on déplore encore parfois. Non, les Lumières ne sont pas «la cause » de la Révolution (Marc Belissa). Oui, la « centralisation jacobine » est un mythe politique péjoratif (Michel Biard). Et non, la Révolution ne fut pas tout entière une dictature politique et judiciaire, mais, si elle est loin d'avoir gommé les inégalités (Jean Bart), elle fut aussi un laboratoire de démocratisation et de laïcisation comme le montrent, pêle-mêle, les contributions de Malcolm Crook, Serge Aberdam, Danièle Pingué, Eric Wauters, Hervé Leuwers, Jacques Guilhaumou, Annie Crépin et Philippe Bourdin. Pour être utiles, ces nombreux rappels ne surprendront pourtant pas les spécialistes de la période.

4 Certaines synthèses sont plus inédites (on retiendra celle de Jean-Luc Chappey sur l'école) voire audacieuses (la contribution d'Annie Duprat sur l'imaginaire politique atteint le tour de force pédagogique) ou délibérément provocatrices («Les nobles victimes de la Révolution?» par Karine Rance, «Une Révolution sans ou contre les paysans? » de Jean-Pierre Jessenne). L'ensemble montre que l'histoire de la Révolution s'est ouverte à de nouveaux champs, issus des études postcoloniales (article de Marcel Dorigny et Bernard Gainot sur la " question coloniale ») et de l'histoire du genre, même si cette dernière se traduit souvent en France par une histoire des femmes ( Une absence de révolution pour les femmes ", par Martine Lapied). Alors que le grand public est invité au déplacement du débat sur la « Terreur » vers celui sur les violences (JeanClément Martin) ou à méditer sur l'intégration de la contre-révolution à l'histoire "positive» de la Révolution (Valérie Sottocasa), il peut continuer d'observer l'ouverture de l'historiographie française aux espaces extra-nationaux (contributions de Jean-Paul Bertaud, Pascal Dupuy et Alan Forrest) ainsi qu'à la réévaluation de la période directoriale dans la construction de la République (Pierre Serna). En retraçant deux siècles d'histoires de la Révolution dans l'article de clôture, Claude Mazauric propose enfin un tour d'horizon très utile en dénaturalisant les grands récits aux yeux du public.

5 Bien sûr, il sera toujours possible de critiquer le caractère un peu hexagonal de cette somme, presque entièrement rédigée par des auteurs français. Or cette limite n'est pas due à un repli, mais aux urgences éditoriales de cette entreprise, pensée en réaction au Livre Noir de la Révolution française (2008). Ouvert par Michel Vovelle et refermé par Claude Mazauric, ce livre peut aussi donner l'impression aux non spécialistes ou aux historiens d'autres périodes d'être l'expression un peu réductrice d'une école de pensée. Toutefois, le large éventail des thèmes abordés, la présence de contributeurs de sensibilités diverses, la prépondérance des thèmes consacrés au champ politique ainsi 
que l'usage constant de la méthode historiographique dans les contributions, démontrent qu'au-delà des mots d'ordre de rigueur, les interprétations concurrentes (on pense évidemment à Furet) sont en réalité non seulement prises en compte, mais pleinement intégrées. Vingt ans après 1989, l'histoire engagée de la période révolutionnaire a dépassé les apories dans lesquelles le Bicentenaire l'avait laissée et même parfois discréditée. Au prix d'un profond renouvellement, cette somme montre qu'elle se porte aujourd'hui plutôt bien. 